\title{
Neodymium Magnetic Shock Absorber for Two Wheelers Automobiles
}

\author{
B Nandish, K P Muthanna, M B Kaveriappa, P S Biddappa
}

\begin{abstract}
This paper presents a research work on magnetic suspension system of two wheelers Automobiles, which are usually depending on spring type, Hydraulic and Pneumatic suspension systems. In this proposed magnetic suspension system, two permanent magnets made of Neodymium material are placed inside the shock absorber cylinder such that both facing same pole. So they produce a repulsive magnetic flux force, when they come closer due to shocking load. This repulsive magnetic flux force is used as shock absorbing media and provides damping force. Proposed suspension system proves to be more efficient over other type of suspension systems, absorb more number of shocks with high accuracy, has no leakage problem unlike in Hydraulic and Pneumatic system. So all these beneficial qualities make the magnetic suspension system to work efficiently with less maintenance cost and hence the Automobile.
\end{abstract}

\section{INTRODUCTION}

Shock absorber is a mechanical member, fitted on and held between wheel and body of the automobile. Its primary function is to absorb shocking force emerging from wheel of Automobile, when wheel moves over road irregular surfaces. Hence shocking force is prevented to reach body of vehicle and rider of vehicle feels comfort. Main types of suspension system are Mechanical spring type, Hydraulic type, Pneumatic type. In current days, magnetic suspensions system is used because of its many advantageous over other systems. Present work consists of design and analysis of magnetic suspension system, which is used in two wheeler automobiles.

\section{DESCRIPTION OF NEODYMIUM MAGNET.}

It is a permanent magnet formed with alloy of Neodymium, Iron and Boron. It is having $\mathrm{Nd}_{2} \mathrm{Fe}_{14} \mathrm{~B}$ tetragonal crystalline structure and is commercially available in many grades. Grade used in the present work of suspension system is N4518, easy availability and desirable properties are the reason to choose this grade. It's important properties are shown in Table 1.

Revised Manuscript Received on July 18, 2019.

B Nandish, Assistant Professor, Mechanical Engineering Department, Coorg Institute of Technology, Ponnampet , 571216, India. (nandishb77@gmail.com)

K P Muthanna, Assistant Professor, Mechanical Engineering Department, Coorg Institute of Technology, Ponnampet, 571216, India. (kp.muthanna89@gmail.com)

M B Kaveriappa, Assistant Professor, Mechanical Engineering Department, Coorg Institute of Technology, Ponnampet, 571216, India. (kaveriappa17@gmail.com)

P S Biddappa Assistant Professor, Mechanical Engineering Department, Coorg Institute of Technology, Ponnampet, 571216, India. (biddubellu@gmail.com)
Table 1. Importantproperties of Neodymium magnet of grade $\mathbf{N 4 5 1 8 .}$

\begin{tabular}{|c|c|}
\hline Parameter and its unit & Values \\
\hline Remanence $(\mathrm{T})$ & 1 to 1.3 \\
\hline Co-ercivity $(\mathrm{MA} / \mathrm{m})$ & $0.875-1.99$ \\
\hline Relative permeability & 1.05 \\
\hline Compressive strength $\left(\mathrm{N} / \mathrm{mm}^{2}\right)$ & 1110 \\
\hline
\end{tabular}

\section{DESIGN OF MAGNETIC SUSPENSION SYSTEM.}

In the present work of suspension system, two permanent magnets made of Neodymium are placed end to end inside the shock absorber cylinder, such that both magnets face same pole and a considerable air gap is allowed between them. These magnets are mounted individually on ends of two piston rods of shock absorber. Among two piston rod, one is connected to wheel of vehicle, hence it move along with wheel, other piston rod is connected to body of vehicle and it is fixed. Since both magnets face same pole, a magnetic repulsive flux force is generated between them. This repulsive force is used as shock absorbing media. In the course of working of this suspension system, if the wheel of vehicle moves over road surface irregularities, wheel would move up and down, this in turn causes the piston rod which is connected to it to reciprocate linearly inside the shock absorber.Hence magnet on it moves closer to other magnet, which is on another piston rod. So a repulsive magnetic flux force is generated, this repulsive force shove the movable magnet away from fixed one and constrains action of moving piston rod. As a result, displacement force of wheel is prevented from reaching to body of Automobile. So rider on it feels a comfort drive. In addition to magnetic suspension, a helical steel spring is also provided inside shock absorber. This spring provides additional suspension support, absorb shocks and prevents magnets from direct collision on severe level of shocking load. Figure 1. shows schematic diagram of magnetic shock absorber. 


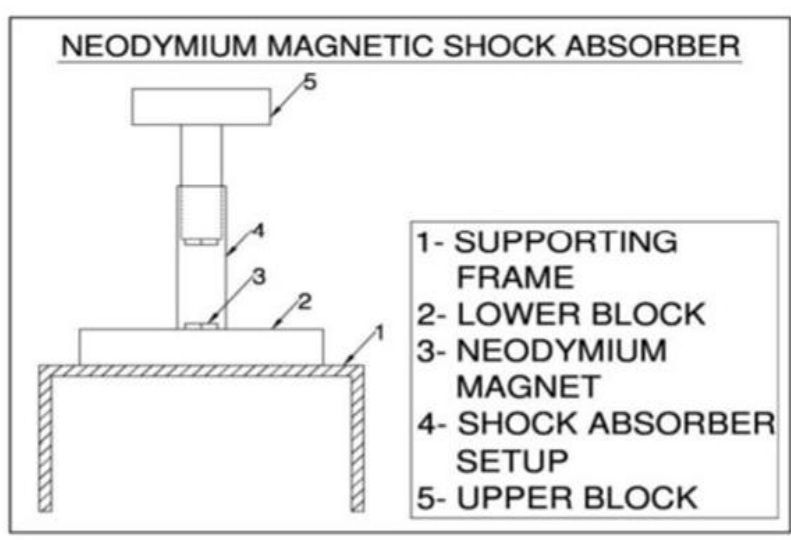

Figure 1. Neodymium magnetic shock absorber.

\subsection{Design of spring used in shock absorber.}

Outer diameter and length of spring are selected based on geometrical requirement of shock absorber. Maximum load sustained by spring is found as follows.

Outer diameter of spring $D_{0}=25 \mathrm{~mm}$, length of spring $\mathrm{L}=82 \mathrm{~mm}$, number of turns $\mathrm{n}=11$, wire diameter of spring $\mathrm{d}=2.5 \mathrm{~mm}$,

Inner diameter $D_{i}=D_{0}-d=25-5=20 \mathrm{~mm}$,

Spring is made of steel and for it, shear stress (from design data book) $=600 \mathrm{~N} / \mathrm{mm}^{2}$.

Spring index $D_{O} / d=25 / 2.5=10$. For this spring index, from design data book, Wahl's correction factor of spring $\mathrm{K}=1.18$.

Load carried by spring $\mathrm{P}=$ shear stress * $\mathrm{K}$

Hence $\mathrm{P}=600 * 1.18=708 \mathrm{~N}$

So, spring can bear load of $708 \mathrm{~N}$, remaining load on shock absorber will be shared by flux power of magnet.

\subsection{Design of magnets used in shock absorber}

Considering a fraction weight of Automobile acting on suspension system (excluding weight of wheel, engine weight and etc. since they are not supported by suspension system $)=15 \mathrm{Kg}=147 \mathrm{~N}$ and weight of person sitting on it = $60 \mathrm{~kg}=588 \mathrm{~N}$.

Total Load $=$ fraction weight of Automobile on suspension system + weight of person sitting on Automobile $=147+588=735 \mathrm{~N}$.

Load on Rear Suspensions $=65$ percentage of total load $=$ $0.65 * 735 \mathrm{~N}=441 \mathrm{~N}$.

Approximating dynamic load as double of total static load $\mathrm{W}=2 * 441 \mathrm{~N}=882 \mathrm{~N}$.

Weight on Single Shock Absorber, W/2 = 441 N, Taking Factor of Safety $=1.2$

So, design $\operatorname{Load}=621.3 \mathrm{~N}$.

Magnetic flux Power per unit Area $=2 \mathrm{~N} / \mathrm{mm}^{2}$, calculated based on Magnetic repulsion Force, as given in section 4.3. So, area of magnet required to bear suspension load of $621.3 \mathrm{~N}$.

$2 \mathrm{~N} / \mathrm{mm}^{2}=621.3 / \mathrm{A}$

Hence $\mathrm{A}=310.65 \mathrm{~mm}^{2}$

Therefore, diameter of magnet required $\mathrm{d}_{\mathrm{m}}=48.1 \mathrm{~mm}=$ $50 \mathrm{~mm}$

\subsection{Calculation of magnetic repulsion force.}

Repulsive force between two magnets is found using Gilbert model of magnetic theory.Equation to find repulsive force $\mathrm{F}$ between two similar cylindrical magnets is given below.

$\mathrm{F}=\left[\mathrm{B}_{\mathrm{o}}{ }^{2} \mathrm{~A}^{2}\left(\mathrm{~L}^{2}+\mathrm{r}^{2}\right) /\left(\pi \mu_{0} / \mathrm{L}^{2}\right)\right]^{*}\left[1 / \mathrm{d}^{2}+1 /(1+2 \mathrm{~L})^{2}-2 /\right.$ $\left.(\mathrm{d}+\mathrm{L})^{2}\right]$

$\mathrm{B}_{\mathrm{O}}$ is flux density at each pole of magnet in tesla. A is area of surface of magnet poles in $\mathrm{m}^{2}, \mathrm{~L}$ is length of each magnet in $\mathrm{m}, \mathrm{r}$ is radius of each magnet in $\mathrm{m}, \mu_{\mathrm{o}}$ is permeability of free space $=4 \pi^{*} 10^{-7} \mathrm{~T}-\mathrm{M} / \mathrm{A}, \mathrm{d}$ is the separation distance between two magnets in $\mathrm{m}$ and it is considerably more than radius $r$ of magnets.

\section{RESULTS AND DISCUSSION}

In the present work, radius of magnet adapted is $r=25$ $\mathrm{mm}$, length of magnet is $\mathrm{L}=12.5 \mathrm{~mm}$. In normal riding conditions of automobile, magnets are apart inside the shock absorber at a distance of $82 \mathrm{~mm}$ and minimum distancewhen they come close during shock is $30 \mathrm{~mm}$. So repulsive magnetic flux force varies from maximum to minimum and it is determined using equation as stated in section 4.3. So, when $\mathrm{x}=30 \mathrm{~mm}$, repulsive force will be maximum $\mathrm{F}_{\max }=$ $5512 \mathrm{~N}$, when $\mathrm{x}=82 \mathrm{~mm}$, repulsive force will be minimum $\mathrm{F}_{\text {min }}=200 \mathrm{~N}$. Results show that, maximum repulsive force $\mathrm{F}_{\max }=5512 \mathrm{~N}$ is greater than load to be bear by suspensions $=441 \mathrm{~N}$. So, newly devised magnetic suspension system can sustain and bear operating load on it.

\section{CONCLUSION}

In the present work, magnetic suspension system has been designed and analyzed. Magnetic repulsive flux force generated by Neodymium magnet confirms to be a good damping media and absorb the shock efficiently. It facilitates lesser maintenance, absence of leakage of oil or air as in other sort of shock absorbers and makes the ride comfort.

\section{REFERENCES}

1. John C Dixon, " The shock absorber handbook ", SAE International, SAE Order No 176, 1999.

2. Suvriti Dhawan and Ravi Nandu, " Magnetic Suspension in Automobiles", Journal of Aeronautical and Automotive Engineering, Print ISSN: 2393-8579, Online ISSN: 2393 8587; Vol. 1, No.1, pp. 20-21, September 2014.

3. S Gopinath, R J Golden Renjith, J Dineshkumar, "Design and fabrication of magnetic shockabsorber", International journal of Engineering and Technology, Vol.3, No.2, pp.208-211, 2014.

4. V V Borole, K K Chaudhari, "A Review on Magnetic Shock Absorber”, E-ISSN: 2348-0831, Vol.2, Issue 3, pp.104-109, Mar-Apr 2015

5. Shende Vignesh, Nimbalkar Hrishikesh , Pawar Sanjay, Thorat Vijay, Raut P S , "Magnetic suspension System for Two-Wheeler", International Journal of Recent Research in Civil and Mechanical Engineering, Vol. 2, Issue 2, pp. 141146, October 2015 - March 2016.

6. Kale A B,Tamhane S V,Totre A S,Wayal P S, Patait S B, "Magnetic Shock Absorber", International Journal of Advance Engineering and Research Development Technophilia, Vol.5, Special Issue 04, Feb.-2018.

7. Aniket Bharambe, “ Magnetic Suspension for Motorcycles", International Journal of Science and

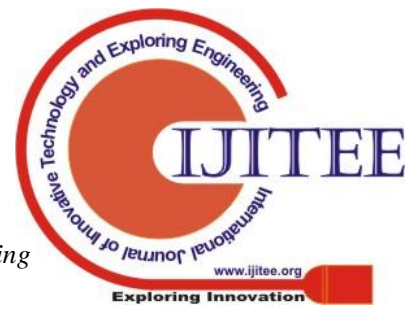


Research, Vol.5 ,Issue 9, Sep 2016.

8. S Duym, R Stiens, and K Reybrouck, "Evaluation of shock absorber models", Vehicle System Dynamics, Vol. 27, no.2, pp. $109,1997$. 